\title{
ETHICS AND SCIENCE: CHALLENGES AND POSSIBILITIES
}

Perhaps the biggest challenge for the relationship of ethics and science is the issue of whether or not it is justifiable to manage human related research (for example, the question of whether we should have a moratorium on research that constitutes dangers to human being and/or humanity) socio-ethically. The author asks the question if such management is principally possible. Scientism and socio-ethical nihilism have increased their influence which manifests itself, among other things, in attempts to seclude 'a unique ethics of science' based on objective postulates of knowledge alone, separated from social praxis as well as from ethical values of humanity. Related to this situation is the fundamental question whether an ethical 'self-regulation' of science, detached from social factors that are foundational for such regulation, is at all possible. Science in and of itself does not enter into a contradiction with some abstract ethical norms: a conflict can only be induced by a specific form of its functioning in relation to concrete historic demands of morality. Another important starting point for our deliberation on this topic is the question what makes (or motivates) scientists concern themselves with moral or social problems of regulating the scientific knowledge and scientific or technological praxis? In addition to a rapid growth of scientific and technological possibilities and the ensuing serious problems of social responsibility, it is also the non-existence of such social institutions that would be able to ensure an effective and sufficiently flexible regulation of scientific research, i.e. institutions that would make it possible to diminish the gap between the interests of science and its socio-ethical consequences. Conclusion: there is no secluded, particular ethics of knowing that would be based on an abstract concept of the objectivity of science.

Keywords: Ethics, science, technology, society, responsibility.

\section{Introduction}

Ethics, science and technology are at first glance different and divergent areas of human activity, but on closer inspection we find that they have many intimate points of contact. If we think about science and technology from the standpoint of philosophy, or in the strict sense of ethics as a philosophical discipline that deals with human behavior by exploring morality and the moral standards, in these cases we can easily become victims of mystification of the philosophical and ethical balance. From this moment on we start wondering what brings one more good and, on the other hand, what seems likely to cause harm and evil.

To one's moral consciousness, when isolated from the social and historical resources of goodness, it may seem that the good and evil in the world are akin to well-defined proportions. For example, some knowledge of science can be used but also abused; a given discovery in the world of human technology can directly or indirectly help or harm. New knowledge and discoveries appear to be beneficial to humans, and yet we must also conclude that false moral principles - promoted by a political power or ideological fanaticism - can critically restrict us in the development of technology or hinder scientific progress.

If our interests in these three areas are simplistically identified with their own benefits to each area separately and if we apply to them the concept of good, we could easily slip into the theory that if we do good for ourselves - that is, if we programmatically build our own territory of interest - it is in principle at the expense of another interest. On the other hand, were we to retreat from these positions in order to promote the interests of another sphere, we cause harm to ourselves. We might get as far as embracing the notion that as the development of science does not take into account the ethical ideas of morality and plays no role in forging moral customs, the acceptance of moral principles could be based on the non-acceptance or the reduced respect for the autonomous regularities of scientific thought.

\footnotetext{
* Dalimir Hajko

Department of Philosophy and Religious Studies, Faculty of Humanities, University of Zilina, Slovakia

E-mail: dhajko@h-h.sk
} 


\section{From Anthropology to Critical Questions of Ethics}

The proposed initial ideas seem to suggest that the overlaps between these areas should be based on a sensitive and thoughtful self-reflection. Cardinal questions derived from our recent study of anthropology give rise to contradictory answers: Can ethics as the science of morality interfere with biology, genetics and the human psyche and, if so, to what extent? Do we, in identifying baselines and determining socio-ethical principles, follow through with our scientific study of human being, especially in cases when direct experiments with humans are necessary? What is actually the ethics of scientific knowledge and how are its various elements correlated with the general ethical values of humanity?

Many scientists raise the question of the socio-ethical governance of research on humans. Many have already commented on the question of the admissibility of a moratorium on research which threatens humanity. We are, however, entitled to ask another question: Is such management of research (associated with inevitable restrictions) in principle at all possible, is it appropriate and, if so, then in what form? Does it inevitably restrict the freedom of scientific research, stifling promising innovations in their very origin? What is the correlation between this freedom on the one hand and the social and humanistic responsibility of science and scientists on the other? Linked to this is the key problem of the self-regulation of ethical science. Is the "self-regulation" of science based solely on ethical standards possible?

This question can only be answered in the negative, because there can be no real solution to such a dilemma between science and morality that can arise from a holistic understanding of the human world, radically isolated from the social factors that constitute its foundation. Science itself has not come into conflict with abstract ethical standards in themselves but always only with a particular form of its functioning, with the requirements of concrete historical morality, which are, of course, also socially conditioned. "Virtues can only be understood in terms of their relation to the historic community in which they arise" [1, p. 105].

The issue, however, has a broader dimension. What is forcing scientists to address the ethical, moral, or more broadly social problems regulating scientific knowledge and scientific or technical experience? Is it, perhaps, the possibility of a rapid growth of science and technology which gives rise to serious problems of social responsibility? Is it the absence of social institutions that would be able to ensure an effective and sufficiently flexible regulation of scientific research, making it possible to reduce the looming gap between the interests of science and its social and ethical consequences? Or, is it the lack of activity of such institutions? The famous Israeli-American sociologist Amitai Etzioni spoke in this context of "a sentimental, but non-viable sense of responsibility that is much needed, but which must be based on institutions that would support it" [2, p. 187].

\section{The Need for a New 'Social Contract'}

Several authors stress that the "social contract" between science, technology and society must be renewed. "Enthusiasm for such experiments exceeds our moral imagination” [2, p. 187], said the renowned philosopher and ethicist. But precisely this "enthusiasm for experiments" can provoke a conscious or unconscious attempt to manipulate the environment in which we live. A high regard for experimentation, so prized in science especially since the father of empiricism Francis Bacon, often victorious over our ability (before the start of experimentation) to assess the usefulness and safety of our experiments in the long run.

I chose the mental link of Amitai Etzioni mainly because Etzioni is a representative of the so-called theory of communitarianism. He, on the one hand, highlighted social needs, but also emphasized the need to maintain certain rules correctly and adhere to limits in the organization of all segments of society, including science and morality. He sought to find a meaningful balance between individual freedom and responsibility to the community. This involved in particular the issue whether our historically and socially defined society is able to actually assume and execute this responsibility, in other words, what the dominant range of its priorities is.

If the question is not established in this respect, or formulated clearly enough, one will hardly be able more or less convincingly to refute the concepts of scientism, technicism and socio-ethical nihilism. These deficient concepts tend to regard as "evil" whatever limits or prevents the direct operation of autonomous principles of science and technology. Thus, according to extreme scientism, moral principles necessary for the regulation of scientific knowledge are only to be derived from the very process of gaining understanding.

In principle, every thinking person will probably admit that scientific endeavor itself does not automatically entail a more humane type of human personality solely because that particular person is engaged in scientific activity. The contrary is true: "The proud pursuit of objectivity without a recognition of human limitations, and the dimension of subjectivity in the process, has proved to be a dead end that emits the stench of manipulation, loss of human dignity, and finally nihilism. Understanding the limits of reason will help us avoid the pitfall of 'scientism"' [3, p. 25].

However, there is a fairly widespread view in some scientific circles that in science as such there cannot be a legitimate application of ethical criteria, or even axiological approaches in general: science, according to these views, becomes a human value only when the content of its acquired knowledge and the 
corresponding states of human consciousness are beyond any value characteristics [4]. One can say (somewhat simplistically) that the following reasoning is propounded as valid in these extreme, scientistic approaches: <In science there is only one problem: on the basis of existing knowledge, to create new knowledge>.

\section{Towards a New Understanding of the Relationship between Science, Technology and Ethics}

Although I do not feel competent to comment decisively on this relationship, I would like to express the opinion that the peculiarity of the current disputes about the possibilities of a humanistic orientation of science is, in the eyes of the layman, sometimes seen as an unacceptable convergence (or even an identification) of science and technology. Moral and humanistic values of scientific knowledge thus sometimes merge into one single complex although, in principle, they may be fundamentally different approaches to reality.

Technology is understood primarily as "a cultural resource" applied in the context of the acquisition of technical reality. The technique is thus examined within its own theoretical selfreflection in terms of whether it is suitable for satisfying human needs, whether its products can be utilized, measured, calculated, and can serve as useful tools.

For science, its basic mission is to "explore reality such as it is", as it exists independently of human interests and needs, and even in spite of these interests and needs. Access to real science, i.e. science in and "of itself", acutely raises the question of its preservation and reproduction in terms of technical and pragmatic expansion. Especially in the field of ecology and environmental sciences we see tangible expressions of a kind of inner science pathos, a pathos which has a special care for the salvation of being, existing independently of human consciousness and human will.

But who can understand these warnings, who can coordinate the efforts of scientists and technicians with an ethical starting point and the humanistic social preconditions for the formation of human society? Is there any social organization (Note: I do not say "institutions"), which is able to spontaneously provide an ethical evaluation of the results of the efforts of scientists and technicians? These considerations, it seems to me, lead to the conclusion that science itself does not need any moral control in the sense of this (hypothetical) social organization that could and should ensure the connection of science with technology and with the economy in order to harmonize all initiatives in a comprehensive understanding of social structure.

It is quite logical and legitimate (to some degree) that scientism and socio-ethical nihilism make their impact stronger, for example, in their attempts to establish "the special ethics of science" on the basis of objective knowledge that it itself postulates, that is, largely detached from social practice and the overall ethical values of humanity. However, an opposing view according to which there is no special ethics of knowledge that would be based on the concept of the objectivity of science, is also legitimate.

Ever since the ancient times humanity has developed science and technology in all its forms. Yet the question remains whether humans have thereby become better, happier and more content? Have they not succumbed to the tendency of believing that "human life has its meaning rather as an 'immediately-now', i.e. as an 'immediately-present"' [5, p. 122] at the expense of anticipating and hoping for something more complex and fulfilling?

\section{The Limits of Science and the Realms of Art and Mystery}

If we recognize the undeniable boundlessness of the goals of science, we cannot at the same time fail to notice the idea that there are certain human and social parameters (and not just an abstract sort of "cosmic" parameters) of human scientific knowledge. There is variety of ways of its expression, e.g. in terms of an active creative spirit and other ways of understanding it. In the future, science has to inevitably recognize the inherent limitations of the numerous mysteries of the spiritual world as these are experienced existentially by the human individuals. Such phenomena are cognitively processed relatively independently of science. So the realm of these relationships, which is inevitably marked by the idea of creativity brings us to the idea of the "complementarity" of science and art. Thus, more or less inevitably, we come to the conclusion that the ethical nihilism in science is equally incorrect and detrimental, as is the aesthetic nihilism - both destroying the ideal human being as a versatile, advanced, comprehensive personality. We should instead strive for the ideal of harmony: harmony of all that is "human in man", including science and art as basic forms of human activity in the spiritual realm. A key concept in this context is the concept of creation, creativity, as a specific approach to human reality.

A well-known theory pertaining this issue was authored by a British scientist and writer Charles Percy Snow recently. It is popularly known as the theory of "two cultures". According to Snow's classification, scientists fall under the category of "new culture' - not only in the intellectual, but also in the anthropological sense - Culture created by science. Artistic intelligentsia continues to remain in the 'traditional' culture. This polarization of culture is in Snow's view an apparent loss for all of us, affecting us on practical, moral and creative levels of functioning [6].

Both science as well as the culture seek language with which to describe human experience. They are looking for concepts, words and images, exempting things and events from the captivity of silence and muteness. Human language condenses our intellectual reflection and interpretation into perceptible forms and shapes. 
On the foundation of these relationships, which are inevitably marked by the idea of creativity, we get not only the idea of "complementarity" of science and art, but also the need for the formation of the so-called 'third culture', as John Brockman suggests [7]. Thus, more or less inevitably, we come to the conclusion that ethical nihilism imposed on science and aesthetic nihilism imposed on the arts are essentially equally wrong. We should rather strive for the embodiment of an ideal of harmony: the harmony of all that is human in each human being, including science and art as basic forms of human activity in the spiritual realm. A key concept in this context is the concept of creation, creativity, as a specific approach to human reality.

Only with a considerable dose of naivety could we say today that man approximates to these values and ideals. Our everyday reality convinces us otherwise - we are constantly moving away from them. However, it is also an indisputable fact that by means of art one may reach beyond rational clarity; art reveals to man the secrets that are inaccessible to rational scientific knowledge. So man needs art as an organic part of what is contained in him and in the world. Niels Bohr said concerning the relationship of science and art that: "The reason why art can enrich us lies in its ability to remind us of the secrets inaccessible to systematic analysis" [8].

The orientation of art on the emotional side of our nature and on the moral world of man produces in art a clearly pronounced sense of philosophical, moral and humanistic formulation of problems of life and death, good and evil, freedom and honor of the human [9].

These problems - as is the case of human beings - do not change as quickly as the scientific discoveries; they are in some sense eternal, as is eternal the art that expresses them. Art is not only a kind of auxiliary instrumentarium of science. Art directly affects the development of creative forces in man. In this context, we should remember Albert Einstein who appreciated the effect of art on the emotional side of man, without which no science can fully exist. He said: "I personally ascribe to a work of art a sense of supreme happiness. I drew from them more mental bliss than from any other area ... Dostoevsky gives me more than any scientific thinker, more than Gauss" [10, p. 81]. Einstein obviously did not want to degrade the importance of one of the greatest mathematicians and physicists of all time, but merely wished to open the way to the point of view that creativity is a higher social and moral determination of man. However, it often requires an internal incentive or an inspiration that can come quite unexpectedly from another area of human self-expression. Revealed in it are the essential forces of man, his abilities and spiritual riches. It is here where we find a possibility of creating new starting points towards understanding the limited sphere of science, technology, ethics and artistic creation.

\section{Human Creativity as a Platform for Harmony}

The concept of "creativity" is not a magic formula; it must be understood more broadly, not only as a scientific or artistic creativity, but also as a development and objectification of all spiritual forces of man. The layout of our own lives is a kind of creativity for which a man takes full responsibility. Creativity understood in the broad sense (as a social and historical dynamic of the objectification of creative forces and human potential) is a discovery of the moral and psychological world of human personality. Through creativity, we deliver and develop not only accumulated knowledge, but also moral values. Only creativity is able to become a platform for harmony in the process of the convergence of science, technology and ethics.

According to the Russian (or more accurately the Estonian and Estonian-Jewish) philosopher, scholar of semiotics and cultural theorist, Yuri Mikhailovich Lotman [11], the current semiotics of art and the semiotics of culture on the one hand, allows one to see a work of art as a peculiarly man-made intellectual shape, and on the other hand to look at culture as a natural and historicallyformed mechanism of collective reason, which disposes collective memory and is able to perform intellectual operations. It thereby ceases to be human intellect, something special, and this is an important step in the development of science. Lotman's 'artonika' - as he called a cybernetic artistic text - may well result not only in a scientific theory but also technical and practical possibilities. It is hoped that the time will come when a careful examination of artistic phenomena and mechanisms of culture will become common even for cybernetics, and for the creators of new forms of technology. The need for a synthesis in this area is also demonstrated by the fact that an increasing number of modern scholars devote themselves to the study of "transmediality" (storytelling through various media, each of which somehow extends the story) and of cultural "autocomunication" (such as communication within a single culture space).

\section{Conclusion}

Searching for lost harmony has been the leitmotif of the relationship between scientific knowledge and ethics, between technology and morality, between science and other forms of perception and explanation of the world, such as art, ever since the era of Humanism. The humanists "became an important force of reform both in the Catholic and Protestant environments" [12, p. 184] changing the nature and content of education, opening the way for a more secular vision of reality, while its holistic nature and interdependencies. Our responsibility today is to embrace this quest. This continuing search, which we might label 'the search for a synthesis', in fact permeates the whole history of human culture. The story of the relationship between science, technology and ethics acquires a new dimension when seen against this backdrop. 


\section{References:}

[1] VALCO, M., KRALIK, R., BARRETT, L.: Moral Implications of Augustine's Philosophical and Spiritual Journey in his Confessions. Communications - Scientific Letters of the University of Zilina, vol. 17, No. 2, 2015, 103-108. ISSN 1335-4205.

[2] ETZIONI, A.: The Normativity of Human Rights is Self-Evident. Human Rights Quarterly, vol. 32, No. 1, 2010, 187-197, ISSN 0275-0392; See e. g.: JUROVÁ, J.: On Etzioni's concept of a responsive community. European J. of Science and Theology, vol. 12, No. 3, 2016, 71-80. ISSN 1841-0464.

[3] VAlCO, M., VAlCOVA, K.: The Epistemological Challenge of Kierkegaard's Truth is Subjectivity Principle. Communications Scientific Letters of the University of Zilina, vol. 16, No. 3, 2014, 25-28. ISSN 1335-4205.

[4] HANES, P. and MASARIK, M.: Complementarity of Science and Theology. European J. of Science and Theology, vol. 12, No. 6, 2016, 5-20, ISSN 1841-0464.

[5] DUPKALA, R.: Recentivism of J. Banka as "practicing philosophy in harmony with the Spirit of the Age" (in Slovak). Filozofia, vol. 63, No. 2, 2008, 122-130. ISSN 0046-385X.

[6] SNOW, C. P.: The Two Cultures. London : Cambridge University Press, 1959; SNOW, CH. P.: The Two Cultures. A Second Look. London: Cambridge University Press, 1963. SNOW, CH. P.: Across the Great Divide. In: Nature Physics 5 / 2009, 309.

[7 BROCKMAN, J.: The Third Culture. Beyond the Scientific Revolution. New York: Simon \& Schuster, 1995. ISBN 0-684-82344-6.

[8] BOHR, N.: Atomic Physics \& Human Knowledge. London: Chapman \& Hall, 1958.

[9] Kondrla, Pavlikova and Kralik point out that the Danish philosopher Soren Kierkegaard highlighted the same ideas in the $19^{\text {th }}$ century. See: KONDRLA, P. and PAVLIKOVA, M.: From formal ethics to existential ethics. European J. of Science and Theology, vol. 12, No. 3, 2016, 101-111. ISSN 1841-0464; KRALIK, R.: Kierkegaard and his influence on Tillich's philosophy of religion. European J. of Science and Theology, vol. 11, No. 3, 2015, 183-189. ISSN 1841-0464.

[10] EINSTEIN, A.: My View of the World (in Czech). Praha: Ceskoslovensky spisovatel, 1961.

[11] LOTMAN, J. M.: The Structure of Artistic Text (in Slovak). Bratislava: Tatran, 1990. ISBN 80-222-0188-X.

[12] VALCO, M.: The Roots and Nature of Luther's Theological understanding of 'Missio Dei' in the Context of Reformation Agenda. European J. of Science and Theology, vol. 12, No. 4, 2016, 181-188. ISSN 1841-0464. 